\title{
Design and Development of Modified Starch from Indonesian Cassava (Manihot esculenta Crantz) for Enteric Film Coating Polymer Applications
}

\author{
Y. YUSRIADI, EVI SULASTRI *, N. I. F. RAHMAN, N. AMBIANTI AND NUUR AANISAH \\ Department of Pharmacy, Faculty of Mathematics and Natural Sciences, Tadulako University, Sulawesi Tengah 94148, \\ Indonesia
}

\section{Yusriadi et al.: Starch Modification for Enteric Film Coating Polymer Applications}

\begin{abstract}
The design and development of modified cassava starch from Indonesia for film enteric coating polymer applications were conducted in this study. The cassava starch was physically modified by heating at $\mathbf{7 0}^{\circ}$ to produce pregelatinized cassava starch, followed by chemically modified by esterification to produce pregelatinized cassava starch phthalate. Pregelatinized cassava starch phthalate was formulated to produce film coating polymer with variations of concentration. The results of film coating pregelatinized cassava starch phthalate showed a lower solubility at pH 1.2 and higher at alkaline pH where the optimum results are shown in formula 3 containing pregelatinized cassava starch phthalate with a concentration of $6 \%$ and plasticizer $50 \%$ of the total pregelatinized cassava starch phthalate. The solubility of formula 3 in acidic (pH 1.2) and alkaline medium (pH 7.2) were $11.42 \% \pm 2.06 \%$ and $38.91 \% \pm 2.23 \%$, respectively. The highest film polymer tensile strength and Young's modulus was also shown in formula 3 with value of $1.14 \pm 0.379 \mathrm{MPa}$ and $3.7 \times 10^{-2} \pm 4.4 \times 10^{-3}$. These results suggest that pregelatinized cassava starch phthalate has the potential to be utilized as a controlled release film coating polymer that has good mechanical properties.
\end{abstract}

Key words: Film coating polymer, cassava, modified starch, pregelatinized cassava starch phthalate

The cassava that is used in this study was cassava from Palolo in Sigi Regency. Palolo region is the highest cassava production in Central Sulawesi, Indonesia. The production contribution achieved more than 4261 tons of cassava in 2015. Those high production of cassava has the potential to be developed into a raw material for starch production ${ }^{[1]}$. Thus, the novelty of the research is to utilize the typical resources from Palolo, known as cassava which has been proven to produce starch. Going forward, it encourages innovation to transform natural resources into valuable product thus reduce the imports of pharmaceutical raw materials in Indonesia.

Widely available, starch has been used as a filmforming biopolymer for controlled drug release. However, the use of natural starch has some limitations, such as lack of swelling capacity and unsatisfactory mechanical properties for coating the tablet in certain $\mathrm{pH}$ conditions. Consequently, making it necessary to establish special modifications for natural starches to with stand the release of the active drug substance in

*Address for correspondence

E-mail: evisulas3@gmail.com

January-February 2022 certain areas of the gastrointestinal tract ${ }^{[2,3]}$.

Both physical and chemical modification of starch was carried out in this study to enhance the functional properties of the coating material. The physical modification is accomplished by pregelatinizing through heating the starch above its gelatinized temperature to increasetheswellingcapacity of starchin water.However, the disadvantage of this pregelatinized starch is that it tends to undergo retrogradation and still not suitable for controlled release. Hence, a further modification is needed, namely a chemical modification. Chemical modification of starch is based on the esterification of the hydroxyl group with a carboxylic acid derivative group such as phthalic anhydrate that produces starch This is an open access article distributed under the terms of the Creative
Commons Attribution-NonCommercial-ShareAlike 3.0 License, which
allows others to remix, tweak, and build upon the work non-commercially,
as long as the author is credited and the new creations are licensed under
the identical terms

Accepted 27 January 2022 Revised 18 June 2021

Received 28 February 2021 Indian J Pharm Sci 2022;84(1):99-107 
phthalate. This Pregelatinized Cassava Starch (PCS) phosphate results in the improvement of the film characteristics that increase the polymer's rigidity, a more stable coating due to the lack of tendency to retrograde and change the solubility of starch so that it can be used as a coating material for controlled drug release $\mathrm{e}^{[4-6]}$. Previous research by Santayanon et al. reported that the chemical modification of starch using esterifying reagent, such as acetate, propionate and butyrate acylated, able to improve its mechanical properties and the film formation. Meanwhile, cellulose phthalate as an enteric coating film has the ability to be more soluble in alkaline media than acidic media ${ }^{[7]}$.

In this study, the development of pharmaceutical excipients was carried out using cassava starch. The development was carried out to investigate the potential of cassava starch as enteric coating polymer based on the characteristics of the film produced.

\section{MATERIALS AND METHODS}

Cassava were harvested from Palolo, Sigi Regency and processed in our laboratory. The materials used in this study were Hydrochloric Acid ( $\mathrm{HCl})$, ethanol, glycerol, phthalic anhydride, Sodium Hydroxide $(\mathrm{NaOH})$, sodium sulfate anhydridate, potassium hydrogen phthalate, sodium dihydrogen phosphate and dihydrogen sodium phosphate were purchased from Merck and Co., Inc.

\section{Starch extraction:}

The skin of fresh cassavas (Manihot esculenta Crantz) is removed from harvested cassava tubers then washed thoroughly using running water. The clean tubers are cut into slices and then shredded using a machine until the tubers become smooth. The refined tubers were collected in a container and suspended with distilled water. Afterward, the water is squeezed out and filtered through a flannel cloth; the precipitate was kept in a jar for $24 \mathrm{~h}$. The starch was then oven-dried for $48 \mathrm{~h}$ at $50^{\circ}$, ground gently with a mortar, sifted with 80 mesh sieve $\left(180 \mu \mathrm{m}\right.$ mesh size) and stored at room temperature ${ }^{[8]}$.

\section{Starch modification:}

The pregelatinization of cassava starch to produce PCS: $100 \mathrm{~g}$ of cassava starch are suspended in 200 $\mathrm{ml}$ of distilled water. The suspension is heated at a temperature of $70^{\circ}$ on the hotplate while stirred using a magnetic stirrer at $200 \mathrm{rpm}$ for $10 \mathrm{~min}$. Then, it was dried in an oven at $60^{\circ}$ for $1 \times 24 \mathrm{~h}$. The dried product is finally sieved with mesh $80^{[9]}$.
Esterification to produce Pregelatinized Cassava Starch Phthalate (PCSP): PCSP were prepared by suspending the pregelatinized starch in distilled water to achieve the concentration of $10 \% \mathrm{w} / \mathrm{v}$. The suspension was constantly stirred at $1000 \mathrm{rpm}$ and reacted by adding dropwise $16.67 \%$ phthalic anhydride solution in ethanol every $1 \mathrm{~min}$ (amount of phthalic anhydride is $50 \%$ by weight starch). During the reaction, $10 \mathrm{~N} \mathrm{NaOH}$ solution is added continuously to adjust the $\mathrm{pH}$ level of $8-9$, followed by the addition of $10 \mathrm{mg}$ anhydrous sodium sulfate every $6 \mathrm{~min}$ until the reaction is complete. The reaction is considered to be completed after the phthalic anhydride solution is depleted. The stirring is continued for $60 \mathrm{~min}$. Then the solution is left for $24 \mathrm{~h}$. On the next day, the suspension was neutralized to $\mathrm{pH} 6.5-7$ by adding $1 \mathrm{~N} \mathrm{HCl}$. It was left until some sediment is formed. The sediment that has been formed is washed by using $20 \mathrm{ml}$ of $50 \%$ ethanol for ten times and evaporated at a temperature of $60^{\circ}$. The PCSP formed is then pulverized and sieved with mesh $80^{[4,9]}$.

\section{Characterization of unmodified and modified starch:}

Organoleptic evaluations and morphology: Organoleptic evaluations were carried out on PCS and PCSP obtained to determine the powder's color, shape and odor. The shape and surface morphology of the PCS and PCSP powders were determined using a Scanning Electron Microscope (SEM) (FEI S50 $\left.{ }^{\circledR}\right)^{[10]}$.

Tapped density: Measurement of tapped density was carried out by weighing $10 \mathrm{~g}$ of powder into a $50 \mathrm{ml}$ measuring cylinder and observed the initial volume. Then mechanically, the measuring cylinder was tapped 500 times until the volume of powder reaches the minimum number.

Water content: The amount of the water content, based on SNI 08-7070-2005 was obtained by weighing $2 \mathrm{~g}$ of PCS and PCSP, then heating it to a constant weight $\left(105^{\circ}\right)$. The percentage of water content is determined by the following equation ${ }^{[10]}$.

Water content $=\mathrm{W}-\left(\mathrm{W}_{1}-\mathrm{W}_{2}\right) / \mathrm{W} \times 100 \% \quad$ Eq. 1

Where $\mathrm{W}$ is sample weight; $\mathrm{W}_{1}$ is cup weight+sample weight after drying; $W_{2}$ is cup weight when empty.

Degree of Substitution: A total of $10 \mathrm{mg}$ of PCSP was dissolved in $10 \mathrm{ml}$ of $1 \mathrm{~N} \mathrm{NaOH}$ solution. Then the absorbance was measured at the wavelength of $272 \mathrm{~nm}$ using Ultraviolet (UV)-Vis spectrophotometer 
$\left(\mathrm{CECIL}^{\circledR}\right)$. The phthalate content in PCSP was calculated by entering the absorption obtained into the linear regression equation from the calibration curve of the hydrogen phthalate solution in $1 \mathrm{~N} \mathrm{NaOH}$. The degree of phthalate substitution was calculated using the equation ${ }^{[10]}$.

Degree of Substitution=162 $\times$ Percentage of phthalate/14.900-(148 $\times$ Percentage of phthalate

Eq. 2

Film preparation of PCS and PCSP: The method used for making the film coating was adapted from the method developed by Karki et al. ${ }^{[11]}$. The film coating Formula (F) is shown in Table 1. There are variations of coating agent concentrations from PCS and PCSP. The film solution was made up to $50 \mathrm{ml}$ volume in accordance to each formula. The film solution was prepared by heating the solution on a hot plate under constant magnetic stirring until a thick solution is formed. The viscosity of the film solution was measured with a Brookfield viscometer (DV-II $\left.+\mathrm{PRO}^{\circledR}\right)$ at a speed of $50 \mathrm{rpm}$ using spindle number 3 . Then, it is left for $1 \mathrm{~h}$ to remove the air bubbles. The film solution is then poured into a petri dish and dried at $55^{\circ}$ in an oven for $18 \mathrm{~h}$ until a film is formed and can easily be removed from the dish. Finally, the films were cut into pieces of $3 \times 3 \mathrm{~cm}$.

\section{Characterizations of film coating polymer:}

Organoleptic observations and morphology: Organoleptic observations were carried out on PCSP and PCSP film coatings including observations of the shape, color and smell of the film coating. The shape and surface of the PCS and PCSP films were observed using a SEM $\left(\text { FEI S50 }{ }^{\circledR}\right)^{[3]}$.

Film weight and thickness: To obtain the film weight, the film was weighed individually on a digital balance. Then the average weight for each film formula was calculated. Measurement of film thickness was determined using a digital calipers, in which the size of the film coating was $3 \times 3 \mathrm{~cm}$. Measurements were made at three different locations to obtain the average number of film thickness ${ }^{[3]}$.

Folding endurance: The film folding endurance was determined by folding repeatedly the film at the same location up to 300 times or until the film is torn. The number of folds in the film in the same place before tearing is the value of the folding endurance. The method was done in three random films of each formula ${ }^{[3]}$.

Film solubility: Film solubility was conducted using artificial gastric and intestinal fluids. To assess the solubility of film in gastric fluid, the film was incubated in $50 \mathrm{ml}$ of $0.1 \mathrm{~N} \mathrm{HCl}(\mathrm{pH} 1.2 \pm 0.05)$ at $37 \pm 0.5^{\circ}$ for $2 \mathrm{~h}$. The film was then withdrawn and placed in a desiccator until it reached a constant weight. The solubility of film coating is determined as a percent of the weight of the film lost. Then the films were placed into a 100 $\mathrm{ml}$ beaker glass filled with $50 \mathrm{ml}$ of $0.02 \mathrm{M}$ phosphate buffer ( $\mathrm{pH} 6.8 \pm 0.05$ ), followed by incubation for $3 \mathrm{~h}$ at $37 \pm 0.5^{\circ}$. Then samples were withdrawn and dried to constant weight in the desiccator. The test was repeated again in intestinal fluids with a phosphate buffer $(\mathrm{pH}$ $7.4 \pm 0.05$ ) at $37 \pm 0.5^{\circ}$. The film solubility was expressed as follows formula ${ }^{[12]}$.

Percentage (\%) solubility $=\mathrm{X}_{\mathrm{o}}-\mathrm{X}_{\mathrm{A}} / \mathrm{X}_{\mathrm{A}} \times 100 \%$

Where $X_{o}$ and $X_{a}$ are the initial and final weight of film, respectively.

Fourier Transform Infrared (FT-IR) spectroscopic analysis: The FT-IR spectra of F1-F5 film and the PCSP powder were generated by a FT-IR spectrophotometer (IR Prestige-21 from Shimadzu). The sample was prepared in potassium bromide disks. The absorption of sample was recorded with wavenumbers ranging from 4000 to $350 \mathrm{~cm}^{-1}$ at a resolution of $4 \mathrm{~cm}^{-1}$.

\section{Statistical analysis:}

All data were analyzed by one-way Analysis of Variance (ANOVA) using Statistical Package for the Social Sciences (SPSS) software, (SPSS 17.0 for Windows).

\section{TABLE 1: THE FORMULAS OF PCP AND PCSP FILM COATING}

\begin{tabular}{lccccc}
\hline S. No. & PCSP & PCS & Glycerin & Distilled water & Formula \\
\hline 1 & $4 \%, 5 \%$ & - & $50 \%$ from PCSP & Added up to $100 \%$ & F1 \\
2 & $5 \%$ & - & $50 \%$ from PCSP & Added up to $100 \%$ & F2 \\
3 & $6 \%$ & - & $50 \%$ from PCSP & Added up to $100 \%$ & F3 \\
4 & $6 \%$ & - & $40 \%$ from PCSP & Added up to $100 \%$ & F4 \\
5 & - & $6 \%$ & $50 \%$ from PCS & Added up to $100 \%$ & F5 \\
\hline
\end{tabular}




\section{RESULTS AND DISCUSSION}

In this study, modified cassava starch was obtained by the pregelatinized-esterification process. The modified cassava starch powder obtained yields for pregelatinized and pregelatinized-esterification are $88 \%$ and $70 \%$, respectively. The pregelatinizing process was carried out by heating the starch in excessive water that resulted in molecular changes. Heat allows the water to diffuse into the starch granule and swells substantially due to the amorphous phase's hydration, whereas esterification produced phthalate pregelatinized starch. Esterification is a chemical modification done by substituting the carboxylate group on the starch hydroxyl group to produce starch phthalate. This process aims to change the solubility of starch in the physiological alkaline atmosphere of the body so that it can be used as a drug coating agent with a controlled release system ${ }^{[6]}$.

Characterization of cassava starch powder with and without modification is described below. The obtained PCS powder was white, fine powder and has a distinctive odour of starch, while the PCSP powder was white in color and odorless. Based on Indonesian Pharmacopoeia in $5^{\text {th }}$ edition, the result shows the same

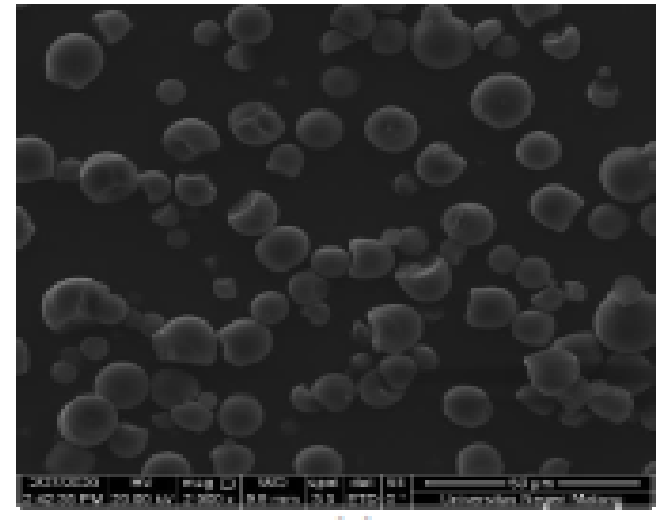

(a) results as the organoleptic test of unmodified cassava starch and modified cassava starch ${ }^{[13]}$.

The powder results from the combination of both physical and chemical modification and was characterized to observe the quality of the powder. The obtained powder was characterized physically in terms of organoleptic, morphology, tapped density and moisture content, while for the chemical characteristics, the degree of substitution test was carried out.

As shown in fig. 1, the morphology of cassava starch granules obtained based on SEM with the magnification of $2000 \times$ is irregularly rounded. In the observations of cassava starch granules, which did not undergo any modifications, the granules shape is separated without any aggregation. Unlike the pregelatinized modified starch granules, it appears to aggregate. This shows that the starch undergoes a pregelatinized process ${ }^{[14]}$. The observations of pregelatinized-esterified starch granules show that more starch is able to aggregate due to repeated heating processes that break the structure of starch granule $\mathrm{e}^{[15]}$.

The results of the tapped density of PCS and PCSP powders were described in Table 2, which shows that

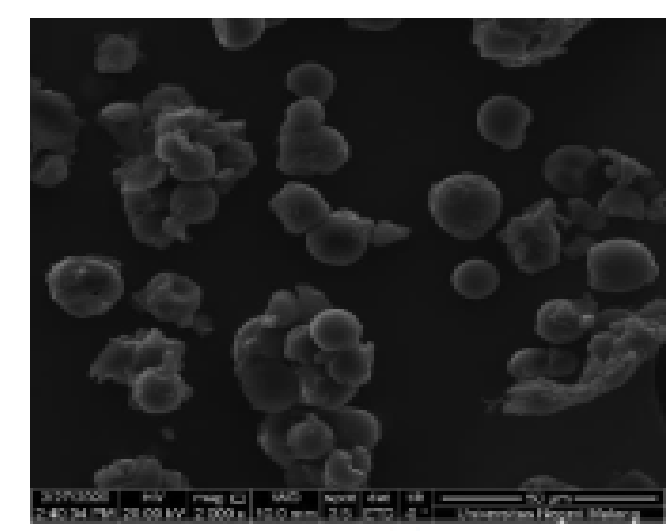

(c)

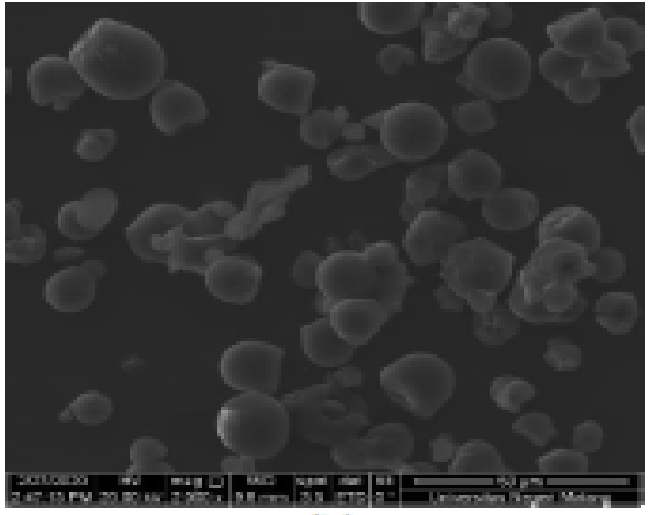

(b)

Fig. 1: The morphological form of starch powder without modification, (a) Pregelatinized starch powder; (b) Phthalate pregelatinized starch powder; (c) Magnification (2000 $\times$ ) by SEM 
PCSP is more compressible than PCS. This is due to the esterification process, which was done by stirring the suspension at $1000 \mathrm{rpm}$ for $120 \mathrm{~min}$, resulting in a more porous particle so that PCSP is useful in various processing methods such as granulation and direct compression $^{[16]}$.

The water content was determined by heating starch powder at a temperature of $105^{\circ}$ to constant weight, as displayed in Table 2. The result shows that PCSP had higher water content than PCS. However, these results were not significantly different and still categorized as the moisture content value for Manihot esculenta that stated in Pharmacopeia specification, which was not more than $16 \%{ }^{[13]}$.

The substitution degree of PCSP powder was carried out to determine the number of phthalate groups that react to the starch's hydroxyl groups. Phthalate levels in PCSP were measured by the UV-Vis spectrophotometric method at a wavelength of $272 \mathrm{~nm}$. The wavelength was determined from a calibration curve in $1 \mathrm{~N} \mathrm{NaOH}$. The results were obtained after plotting the absorbance of solution into the calibration curve. The value of the degree of substitution of 0.0018 was obtained. The value of 0.0018 indicates the presence of 1 phthalate molecule for every 1000 anhydroglucose units. Phthalate substitution is expected to occur in the starch reactive group, namely at $\mathrm{C}$ positions 2,3 and 6 , with the greatest possible substitution at the $\mathrm{C}-2$ position because of the greatest reactivity ${ }^{[17]}$.

The value of the degree of substitution considered as low, in general, the degree value is $0.2^{[18]}$. The esterification reaction occurs in the aqueous medium, which causes some of the phthalic anhydride to decompose into carboxylic acid, namely phthalic acid, which has a lower reactivity than its anhydrous form. Compared to the aliphatic group substitutions such as acetate or propionate, phthalate substitution in starch yields the smallest substitution level. This may be due to the aromatic form of the phthalates being larger than the aliphatic groups. Therefore, it is more difficult for them to penetrate into the molecular structure of $\operatorname{starch}^{[9]}$. Although the value of the degree

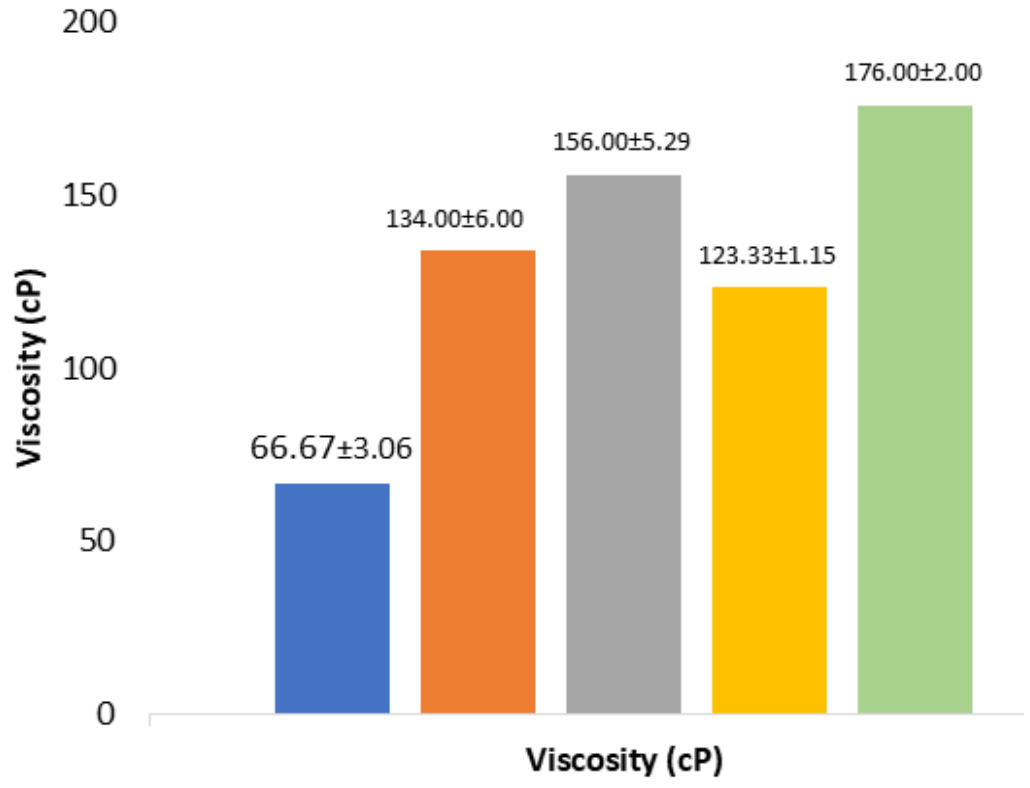

Fig. 2: The viscosity of film coating polymer solutions, $(\square)$ F1; ( ) F2; ( ) F3; ( ) F4; ( ) F5

TABLE 2: RESULTS OF POWDER CHARACTERIZATION

\begin{tabular}{lcc}
\hline \multirow{2}{*}{ Parameter } & \multicolumn{2}{c}{ Mean values of characterization } \\
\cline { 2 - 3 } & PCS & PCSP \\
\hline Extraction yield $(\%)$ & 24.82 & 70 \\
Organoleptic test & White powder with a distinctive smell of starch & White powder, odorless \\
Tapped density $(\mathrm{g} / \mathrm{ml})$ & $0.65 \pm 0.14$ & $0.69 \pm 0.09$ \\
Water content $(\%)$ & $9.59 \pm 0.69$ & $9.73 \pm 0.65$ \\
Substitution degree & - & $0.0018 \pm 0.0008$ \\
\hline January-February 2022 & Indian Journal of Pharmaceutical Sciences & 103
\end{tabular}


of substitution is low, the PCSP film solution's viscosity was lower than that of PCS. The research conducted by Surini et al. ${ }^{[3]}$ elaborated that the substitution of phthalates in pregelatinized starch caused a decrease in viscosity and adhesiveness at a concentration of 6 $\%$. This degree of substitution will affect the functional properties of PCSP, especially its solubility. The higher the degree of substitution, the lower the solubility of PCSP in the acidic medium due to the carboxylic group of phthalates only ionizes under alkaline conditions. This phenomenon allows PCSP to be used to resist the drug release in the stomach ${ }^{[10]}$.

Preparation of the coating film was carried out by combining either PCSP or PCS with various concentration of plasticizer (Table 1). Plasticizers are usually used in the range between $30 \%-50 \%$ of the coating material's concentration. Plasticizers are also essential in the production of film coatings as they are useful in increasing flexibility while minimizing the brittleness of the film coating.

Fig. 2 showed the viscosity of film solution from five different concentrations of either PCS or PCSP as a polymer for enteric-coated tablet with various concentrations of plasticizer. The data shows that the viscosity of the F3 is greater than F1 and F2. This is due to the increasing concentrations of PCSP. The film solution's viscosity greatly affects the flowability of the film solution when it is later applied to the tablet and the thickness of the film coating. Moreover, both high molecular weight polymer and high polymer concentration can affect the characteristic of the film obtained $^{[19,20]}$.

In addition, the concentration of plasticizer also affects the viscosity of the film coating solution, as the viscosity data of the film solution indicates that the viscosity of

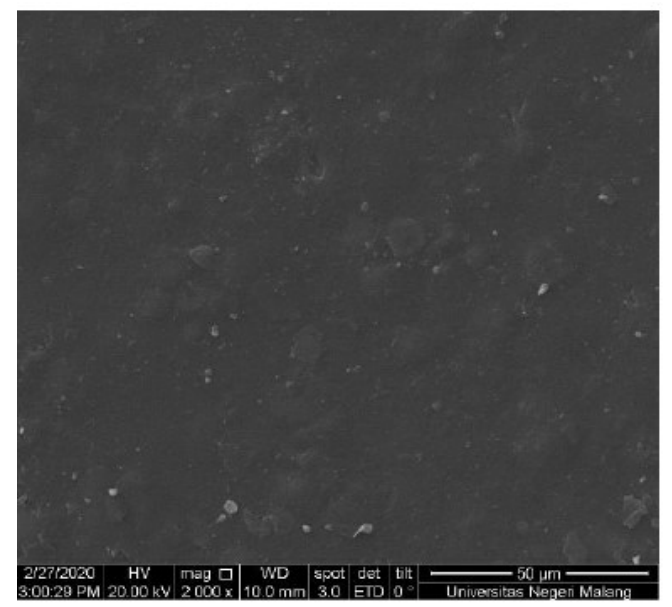

(a) the F4 solution is smaller than F3 and F2. This is related to the concentration of plasticizer in F4 (40\% of the total starch), which is smaller than the concentration of F3 plasticizer ( $50 \%$ of the total starch).

Film coating polymer characterization were conducted on the viscosity of each formula, morphology, folding endurance, tensile strength, weight and thickness of the film and solubility of the film coating in several medium with varying $\mathrm{pH}$. The results are shown in fig. 2, fig. 3 and Table 3.

The organoleptic coatings of PCS and PCSP indicated that the coated films were colorless, odorless and flexible. Even though, the morphology of film coatings containing PCS and PCSP do not significantly differ in texture. However, that cassava starch possessed a rough-shaped with a hollow surface. This shape of the film was due to direct contact with the printed container.

The formulated films thickness and weight were described in Table 3, which shows that F1 film is smaller than the F2, F3, F4 and F5 films because the use of starch as the polymer is the least amount compared to other formulas. Also, the concentration of plasticizer added to affect the thickness of the film. The addition of a plasticizer will increase the polymer that makes up the film matrix as the total dissolved solids increase. Aligned with this finding, Sanyang et al. ${ }^{[21]}$ stated in their research that there was a significant increase in film physical properties against an increase in plasticizer concentration. This is associated with the role of the plasticizer in breaking the polymer chains between molecules, which create more volume or space, as a result, the film thickness and weight increase.

The measurements of the mechanical strength in each formula of the film coatings were carried out by using

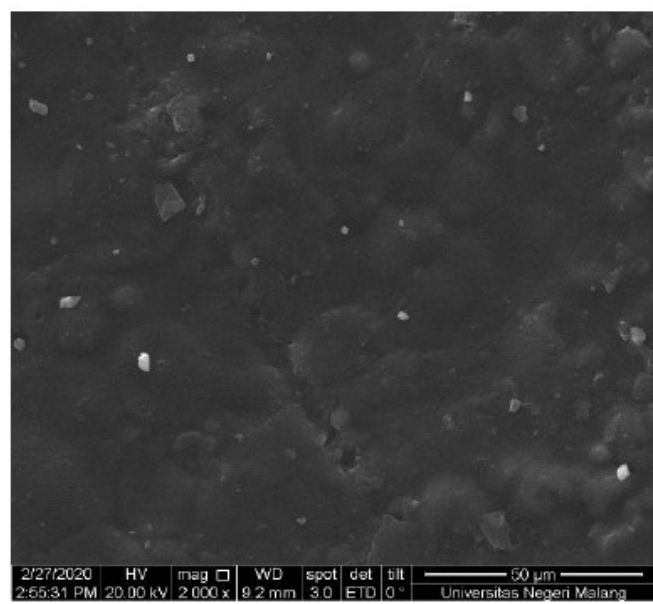

(b)

Fig. 3: SEM micrograph (2000 $\times$ magnification), (a) Film of PCS; (b) Film of PCSP 
the data of tensile strength, elongation and Young's modulus. It can be seen in Table 3 that an increase in the PCSP concentration tends to decrease the value of the mechanical strength of the film coating. The mechanical strength between F3 and F5 proves that chemical modification also affects the mechanical strength of the film coating. The concentration of plasticizer also affects the mechanical strength of the film coating, as proven by the mechanical strength values of F3 and F4. High plasticizer concentration causes the tensile strength value to decrease due to reduced molecular interactions ${ }^{[22]}$. The presence of glycerol as a plasticizer penetrates the film and breaks hydrogen bonds between polysaccharide molecules ${ }^{[23,24]}$.

Evaluation of the film coating's solubility is carried out by incubating the film in a fluid which represented as a gastrointestinal fluid both in the acidic stomach and basic intestine. However, starch is biodegradable which will undergo enzymatic degradation in the digestive tract, allowing starch to be formulated for a controlled release system in the small intestine or colon ${ }^{[25]}$.

The data displayed in Table 3 shows that the higher the starch concentration, the lower its solubility in acidic and alkaline $\mathrm{pH}$ media. The amount of starch content of F3 is larger than the ones in F2 and F1, which causes a decrease in water absorption and solubility. The research of Dimantov et al. stated that the higher the concentration of high amylose corn, the more it will reduce the solubility of the film in the acidic stomach and in the alkaline intestine, also resistant to pancreatic enzymes in the small intestine ${ }^{[26]}$. Meanwhile Surini et al. proved that the combination of starch phthalate and Hydroxypropyl Methylcellulose Phthalate (HPMCP) at a concentration of $5 \%$ was more soluble in alkaline $\mathrm{pH}$ than acidic $\mathrm{pH}$. F3 and F5 have the same concentration as different types of amyilum modification show that the solubility of starch after being modified by phthalate esterification decreases at acidic $\mathrm{pH}$. The presence of free carboxylate groups in starch causes the PCSP film coating to ionize more at alkaline $\mathrm{pH}$. In F3 and F4, the PCSP concentration remains the same, but with different solubility values. F4 has a lower solubility in alkaline medium. This is possible because the concentration of plasticizer is different, whereas in F4 (40\% of the total starch) it is smaller than the concentration of F3 plasticizer $(50 \% \text { of the total amount of starch })^{[10]}$.

The FT-IR spectra for the film and PCSP powder were shown in fig. 4. The Infrared (IR) spectra are used to identify the specific functional groups of the starch. In identifying functional groups, wavelengths from 4000 to $350 \mathrm{~cm}^{-1}$ were used because the absorption radiation of most organic compounds and inorganic ions is within this region. The results of the analysis are given in the form of the intensity of the IR signal relation to the wavelength. Spectra on the PCSP powder detected there is an $\mathrm{O}-\mathrm{H}$ function group at wavenumber $3400 \mathrm{~cm}^{-1}, \mathrm{C}-\mathrm{H}$ at wavenumber $2900 \mathrm{~cm}^{-1}, \mathrm{C} \equiv \mathrm{C}$ at wavenumber $2100 \mathrm{~cm}^{-1}, \mathrm{C}=\mathrm{O}$ at wavenumber 1600 $\mathrm{cm}^{-1}$ and $\mathrm{C}-\mathrm{O}-\mathrm{C}$ at wavenumber $1000 \mathrm{~cm}^{-1}$. This is also the same as indicated by the peak that appears in the F1-F5 film spectra. Despite some small differences, the FT-IR spectra of the samples exhibit the characteristics of starch. The major functional groups shown by starch are hydroxyl groups, alkanes and alkenes ${ }^{[27,28]}$. Moreover, the process of starch modification does not affect the chemical properties of starch.

In conclusion, the characteristics of film coating are influenced by the concentration and modification of starch. F1 and F3 film coated are more soluble in alkaline medium than acidic medium. Thus, PCSP is potential agent as an enteric coating polymer for controlledrelease. Where the best results in this study based on the characterization in the form of organoleptic, morphology, viscosity of the film solution, thickness,

TABLE 3: THE EVALUATION RESULTS OF THE FILM COATING POLYMER

\begin{tabular}{|c|c|c|c|c|c|}
\hline \multirow{2}{*}{ Parameter } & \multicolumn{5}{|c|}{ Average value of the evaluation of the film \pm Standard deviation $(n=3)$} \\
\hline & F1 & F2 & F3 & F4 & F5 \\
\hline Film thickness (mm) & $0.34 \pm 0.02$ & $0.43 \pm 0.02$ & $0.45 \pm 0.01$ & $0.37 \pm 0.01$ & $0.48 \pm 0.01$ \\
\hline Film weight $(\mathrm{g})$ & $0.48 \pm 0.05$ & $0.53 \pm 0.05$ & $0.56 \pm 0.01$ & $0.49 \pm 0.05$ & $0.61 \pm 0.03$ \\
\hline Folding endurance & $>300$ & $>300$ & $>300$ & $>300$ & $>300$ \\
\hline Tensile strength (MPa) & $0.06 \pm 0.013$ & $0.09 \pm 0.006$ & $1.14 \pm 0.379$ & $0.43 \pm 0.544$ & $0.15 \pm 0.008$ \\
\hline Elongation (\%) & $19.22 \pm 3.70$ & $26.12 \pm 4.94$ & $30.35 \pm 8.38$ & $22.31 \pm 5.14$ & $46.79 \pm 8.60$ \\
\hline Young's modulus & $3.3 \times 10^{-3} \pm 6.3 \times 10^{-4}$ & $3.3 \times 10^{-3} \pm 4.9 \times 10^{-4}$ & $3.7 \times 10^{-2} \pm 4.4 \times 10^{-3}$ & $1.6 \times 10^{-2} \pm 1.8 \times 10^{-2}$ & $3.3 \times 10^{-3} \pm 6.2 \times 10^{-4}$ \\
\hline \multicolumn{6}{|l|}{ Solubility (\%) } \\
\hline $\mathrm{HCl}, \mathrm{pH} 1.2$ & $15.37 \pm 1.44$ & $13.57 \pm 2.61$ & $11.42 \pm 2.06$ & $10.15 \pm 1.23$ & $33.21 \pm 2.25$ \\
\hline Phosphate buffer, pH 6.8 & $29.49 \pm 0.92$ & $32.88 \pm 2.13$ & $36.77 \pm 1.47$ & $20.67 \pm 3.42$ & $33.19 \pm 0.68$ \\
\hline Phosphate buffer, pH 7.4 & $35.24 \pm 3.99$ & $37.08 \pm 3.16$ & $38.91 \pm 2.23$ & $20.91 \pm 2.63$ & $30.48 \pm 3.25$ \\
\hline
\end{tabular}




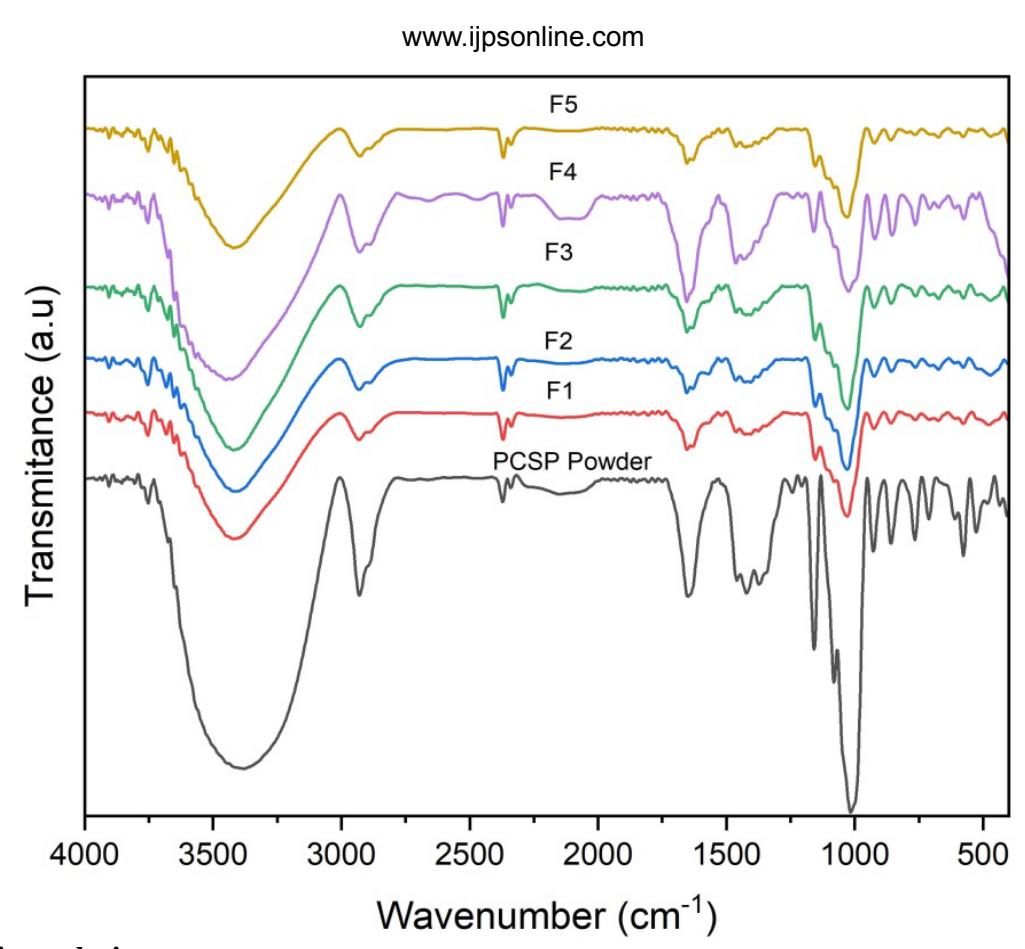

Fig. 4: FT-IR spectroscopic analysis

film weight and film solubility were seen in PCSP and plasticizer with a concentration of $6 \%$ and $50 \%$ of the total PCSP, respectively.

\section{Acknowledgements:}

The authors would like to thank the Tadulako University that financially supported this study via grant scheme of Hibah Penelitian Unggulan-2020 with number 4007/ $\mathrm{UN} 28 / \mathrm{KP} / 2020$.

\section{Conflict of interests:}

The authors declared no conflict of interest.

\section{REFERENCES}

1. Central Bureau of Statistics. Harvested area, production and productivity of cassava and sweet potato by regency/ municipality in Sulawesi Tengah province, 2015. Central Sulawesi Provincial Statistics Agency 2016.

2. Chen Q, Yu H, Wang L, ul Abdin Z, Chen Y, Wang J, et al. Recent progress in chemical modification of starch and its applications. RSC Adv 2015;5(83):67459-74.

3. Surini S, Gotalia F, Putri KS. Formulation of mucoadhesive buccal films using pregelatinized cassava starch phthalate as a film-forming polymer. Int J Appl Pharm 2018;10(1):225-9.

4. Tian S, Chen Y, Chen Z, Yang Y, Wang Y. Preparation and characteristics of starch esters and its effects on dough physicochemical properties. J Food Qual 2018:1-7.

5. Alcázar-Alay SC, Meireles MA. Physicochemical properties, modifications and applications of starches from different botanical sources. Food Sci Technol 2015;35:215-36.

6. Zia-ud-Din, Xiong H, Fei P. Physical and chemical modification of starches: A review. Crit Rev Food Sci Nutr 2017;57(12):2691-705.

7. Ali SF, Afrooz H, Hampel R, Mohamed EM, Bhattacharya R,
Cook $\mathrm{P}$, et al. Blend of cellulose ester and enteric polymers for delayed and enteric coating of core tablets of hydrophilic and hydrophobic drugs. Int J Pharm 2019;567:118462.

8. Duan X, Han H, Deng R, Wu P. Drying treatments on Chinese yam (Dioscorea spp.) prior to wet milling influence starch molecular structures and physicochemical properties. Food Hydrocoll 2020;102:105599.

9. Putra IG, Murwanti R, Rohman A, Sulaiman TS. Physical and chemical properties of native and fully pregelatinized cassava starch (Manihot esculenta Crantz). Indones J Pharm 2018;29(3):145-56.

10. Surini S, Putri KS, Anwar EF. Preparation and characterization of pregelatinized cassava starch phthalate as a $\mathrm{pH}$-sensitive polymer for enteric coated tablet formulation. Int $\mathrm{J}$ Pharm Pharm Sci 2014;6:17-23.

11. Karki S, Kim H, Na SJ, Shin D, Jo K, Lee J. Thin films as an emerging platform for drug delivery. Asian J Pharm Sci 2016;11(5):559-74.

12. Lin SJ, Pascall MA. Incorporation of vitamin $E$ into chitosan and its effect on the film forming solution (viscosity and drying rate) and the solubility and thermal properties of the dried film. Food Hydrocoll 2014;35:78-84.

13. Directorate General of Pharmaceutical and Medical Devices. Indonesian Pharmacopoeia 6th ed. Jakarta: Ministry of Health; 2020.

14. Lefnaoui S, Moulai-Mostefa N. Synthesis and evaluation of the structural and physicochemical properties of carboxymethyl pregelatinized starch as a pharmaceutical excipient. Saudi Pharm J 2015;23(6):698-711.

15. Liu K, Hao Y, Chen Y, Gao Q. Effects of dry heat treatment on the structure and physicochemical properties of waxy potato starch. Int J Biol Macromol 2019;132:1044-50.

16. Krstic MA, Maksimovic Z, Ibric S, Bakic TA, Prodanovic JO, Razic S. Lignocellulosic biomass as a source of microcrystalline cellulose-chemical and technological characterization and future perspectives. Cellulose Chem Technol 2018;52:577-88.

17. Yang C, Lin Y, Cheng F, Zhou M, Tan L, Zhu P. Synthesis and characterization of corn starch phthalate by a semidry method. 
Starch Starke 2019;71(9):1800315.

18. Trela VD, Ramallo AL, Albani OA. Synthesis and characterization of acetylated cassava starch with different degrees of substitution. Braz Arch Biol Technol 2020;63:1-13.

19. Zaid AN. A comprehensive review on pharmaceutical film coating: Past, present and future. Drug Des Devel Ther 2020;14:4613-23.

20. Seo KS, Bajracharya R, Lee SH, Han HK. Pharmaceutical application of tablet film coating. Pharmaceutics 2020;12(9):853.

21. Sanyang ML, Sapuan SM, Jawaid M, Ishak MR, Sahari J. Effect of plasticizer type and concentration on physical properties of biodegradable films based on sugar palm (Arenga pinnata) starch for food packaging. J Food Sci Technol 2016;53(1):32636. [Crossref]

22. Sanyang ML, Sapuan SM, Jawaid M, Ishak MR, Sahari J. Effect of plasticizer type and concentration on tensile, thermal and barrier properties of biodegradable films based on sugar palm (Arenga pinnata) starch. Polymers 2015;7(6):1106-24.
23. Farahnaky A, Saberi B, Majzoobi M. Effect of glycerol on physical and mechanical properties of wheat starch edible films. J Texture Stud 2013;44(3):176-86.

24. Ploypetchara T, Gohtani S. Effect of sugar on starch edible film properties: Plasticized effect. J Food Sci Technol 2018;55(9):3757-66.

25. Lan X, Xie S, Wu J, Xie F, Liu X, Wang Z. Thermal and enzymatic degradation induced ultrastructure changes in canna starch: Further insights into short-range and long-range structural orders. Food Hydrocoll 2016;58:335-42. [

26. Dimantov A, Kesselman E, Shimoni E. Surface characterization and dissolution properties of high amylose corn starch-pectin coatings. Food Hydrocoll 2004;18(1):29-37.

27. Edhirej A, Sapuan SM, Jawaid M, Zahari NI. Preparation and characterization of cassava bagasse reinforced thermoplastic cassava starch. Fibers Polym 2017;18(1):162-71. [

28. Fasuan TO, Gbadamosi SO, Akanbi CT. Modification of amaranth (Amaranthus viridis) starch, identification of functional groups and its potentials as fat replacer. J Food Biochem 2018;42(5):e12537. 